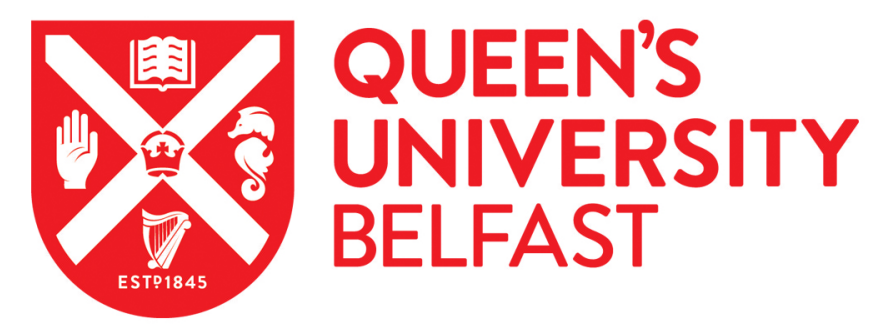

\title{
Relationships Between Deprivation and the Self-reported Health of Older People in Northern Ireland
}

Doebler, S., \& Glasgow, N. (2016). Relationships Between Deprivation and the Self-reported Health of Older People in Northern Ireland. JOURNAL OF AGING AND HEALTH.

https://doi.org/doi:10.1177/0898264316641079

Published in:

JOURNAL OF AGING AND HEALTH

Document Version:

Peer reviewed version

Queen's University Belfast - Research Portal:

Link to publication record in Queen's University Belfast Research Portal

Publisher rights

(c) 2016 The Authors

\section{General rights}

Copyright for the publications made accessible via the Queen's University Belfast Research Portal is retained by the author(s) and / or other copyright owners and it is a condition of accessing these publications that users recognise and abide by the legal requirements associated with these rights.

Take down policy

The Research Portal is Queen's institutional repository that provides access to Queen's research output. Every effort has been made to ensure that content in the Research Portal does not infringe any person's rights, or applicable UK laws. If you discover content in the Research Portal that you believe breaches copyright or violates any law, please contact openaccess@qub.ac.uk. 
Authors:

Dr. Stefanie Doebler

School of Geography, Archaeology and Palaeoecology,

Queen's University Belfast, UK

Phone: +44 7966258646

Email: s.doebler@qub.ac.uk

Dr. Nina Glasgow

Department of Development Sociology

Cornell University, USA

Email:ng14@cornell.edu

Title:

Relationships between Deprivation and the Self-reported Health of Older People in

Northern Ireland.

Accepted for Publication on 22 February 2016 In: Journal of Aging and Health.

Doi:10.1177/0898264316641079 


\begin{abstract}
Objectives: There are few studies on relationships between deprivation and the selfreported health of people aged over 64 years, and no studies fully representative of Northern Ireland's older population. This paper addresses this gap. Methods: Deprivation of older people as reported in the 2001 and 2011 Censuses and the relationship with self-reported health are analyzed over a ten-year span using multilevel modeling. The data are from the Northern Ireland Longitudinal Study (NILS) linked to 2001-11 Census returns. Deprivation measures include housing tenure, property-value, access to a car, educational, employment and area-level income-deprivation. Results: Older people suffering deprivation face a significant health disadvantage over a ten-year time span. Discussion: This health disadvantage is stronger in men than in women, likely due to conservative gender roles prevalent among Northern Ireland's older population, leading to psychological distress among deprived men. The analysis found strongly significant area-level effects, aggravating the health impact of deprivation.
\end{abstract}

Key words for indexing:

Deprivation, poverty, health, Northern Ireland, Census 


\section{Introduction}

Deprivation and its association with the health of older people is an area of increasing interest in the sociology of ageing and in rural sociology. A renewed interest of policymakers, funders and the public in deprivation and its effects on wellbeing and health has arisen in the aftermath of the 2008-recession, resulting in a number of studies on Great Britain (Bécares, Nazroo, Albor, Chandola, \& Stafford, 2012; Lang et al., 2009; MacInnes, Aldridge, Bushe, Tinson, \& Born, 2014; Walsh, Scharf, Cullinan, \& Finn, 2012) and a few on Northern Ireland (MacInnes et al., 2014; McGill, 2014; Walsh et al., 2012; Walsh \& Ward, 2013). Academic and policy reports (McGill, 2014; Walsh et al., 2012) have found macro-level associations on the small-area-level both in Northern Ireland and the Republic of Ireland, most of them based on aggregated Census data. But there is a dearth of individual-level data representative of Northern Ireland's older population. Hence, only scant empirical evidence is available on relationships between deprivation and the health of older people in Northern Ireland. This paper attempts to fill this gap in the literature by describing and analyzing the relationships between several measures of individual and area-level deprivation and ill-health for the population aged 65 years and older of Northern Ireland.

\section{Conceptualizing Deprivation}

The concept of deprivation is close in meaning to the notion of relative poverty and is often used synonymously. However, poverty is the more encompassing concept in the literature, while the notion of deprivation seems to have been introduced in the literature toimprove its measurement (Townsend, 1987). Early studies in the UK used a concept of absolute poverty measured purely via a threshold-value of income, but later conceptual development emphasized the fact that poverty is not just reflected in low income but also in an inability to participate in normal social activities due to a lack of material, cultural and/or financial resources, which has been captured in the concept social exclusion (Callan, Nolan, \& Whelan, 
1993; Townsend, 1987). Today, measures of relative poverty are often studied alongside measures of absolute poverty (MacInnes et al., 2014; Nolan \& Whelan, 1996; Scharf \& Keating, 2012b; Walsh et al., 2012). The concept of deprivation is multidimensional and is measured by a multitude of individual and contextual indicators. Deprivation has been operationalized as consisting of social, educational, employment, material, housing, and transport dimensions.

We adopt the term deprivation rather than poverty, mainly because our data do not contain sufficient measures to fully capture poverty (e.g. we do not have a measure of income). Our data, however, do contain measures of several dimensions of deprivation, each of which contribute to poverty. The analysis of this paper focuses on measuring educational, material, housing, and transport deprivation of older people in Northern Ireland. In addition, we use two known measures of area-level deprivation supplied by the Northern Ireland Statistics and Research Agency (NISRA) that have been discussed in ongoing policy discourses on deprivation (Payne \& Abel, 2012).

\section{Ageing and Individual Deprivation}

Northern Ireland's population is ageing, following the general trend of declining fertility and increasing life-expectancy in most developed countries (Champion \& Shepherd, 2006; Lowe \& Speakman, 2006). By 2025 the number of adults aged 65 years and older will account for $20 \%$ of Northern Ireland's population (Ahern \& Hine, 2012, p. 28). Thus the wellbeing and health of older people is of increasing societal importance, and the UK has a need to measure and monitor deprivation at older ages (Walsh et al. 2012; Scharf \& Bartlam 2008). This is even more the case in Northern Ireland, which like the rest of the UK has experienced an increase in deprivation and poverty across all age groups in the aftermath of the recession. The latest policy reports by the Joseph Rowntree Foundation mention increases in deprivation and poverty for the years 2013 and 2014 (MacInnes et al., 2014). Although in 
other parts of the UK poverty among older people has decreased, in Northern Ireland in 2012 it was found to have increased by 27\% since 2004 (MacInnes, Aldgridge, Parekh, \& Kenway, 2012).

Individual-level deprivation and poverty were found to be associated with ill-health (Åberg Yngwe, Fritzell, Lundberg, Diderichsen, \& Burström, 2003; Groffen, Bosma, van den Akker, Kempen, \& van Eijk, 2008). This association was found to be linked to experiences of social exclusion (Scharf \& Keating 2012; MacInnes et al. 2014; Scharf \& Bartlam 2008).

\section{Gender Differences}

There is a considerable body of literature on gender differences in health at older ages. The majority of studies found that women have worse self-reported health (Bird \& Rieker 1999, Idler 2003, Crimmins, Kim, \& Solé-Auró, 2011) but also a higher life-expectancy. Arber and Ginn (1993) found that, on average, men generally exhibit worse health in late life than women. Some researchers (Verbrugge 1985, Bird \& Rieker 1999, McDonough \& Walters 2001, Denton, Prus, \& Walters, 2004, Crimmins et al. 2011) noted that gender-health differences depend on health condition, e.g. that cardiovascular diseases and adverse health behaviors such as smoking are more prevalent among men while chronic illnesses such as arthritis are more prevalent among women (Bird \& Rieker 1999, McDonough \& Walters 2001, Crimmins et al. 2011).

As for gender differences in the effect of deprivation, the literature is small and inconclusive. Stafford et al (2004) found that living in a disadvantaged neighborhood has more adverse effects on health for older women than men and Ploubidis, Benova, Grundy, Laydon and DeStavola (2014) found that women who were socio-economically disadvantaged in early life showed a stronger health disadvantage in later life than men, which they relate to gender and class differences in mid-life health behaviors. 
However, a majority found men to be more vulnerable to deprivation-effects over the life-course than women: Umberson, Williams, Thomas, Liu, \& Thomeer (2014) found the racial health-disadvantage in the US to be stronger for men than for women. Arber, Fenn and Meadows (2014) found unemployed middle-aged men to be significantly less healthy than unemployed middle-aged women. Similarly, Adena and Myck (2014) found low income to be more strongly negatively related to health for men than for women. Not surprising is the finding that forms of deprivation that are associated with low achievement and social status, such as unemployment and low income, are more strongly related to ill-health for men than for women. Gender roles such as the man as the breadwinner (Courtenay 2000) are still prevalent in Western societies. Such gender roles lead to social pressures that likely affect men and women differently - being unable to fulfill a socially expected role as the breadwinner may well undermine a man's sense of self-worth and thus be detrimental to his health. Such gender-effects are even more likely when studying older generations, since their socialization included more rigid gender roles than are the norm today. We thus expect to find gender differences in the effect of deprivation indicators on health. In particular, long-term unemployment (including never having worked), living in social housing and having no access to a car are expected to be more strongly negatively related to health for men than for women.

\section{Age as a Moderator}

Some of the literature report that age moderates health effects of poverty and deprivation. An important point mentioned often is that income deprivation and poverty are more persistent at older ages because due to a life-cycle effect older people have a harder time moving into employment or finding alternative sources of income (Walsh et al. 2012, 11; Gilbert, Philip \& Shucksmith 2006; Glasgow \& Brown 1998; Glasgow, Holden, McLaughlin, \& Rowles, 1993; Jensen \& Mclaughlin 1997), due to a declining ability to work, declining 
physical mobility and deteriorating social networks. Moreover, a growing body of literature rooted in cumulative disadvantage theory (Merton 1968, Dannefer 2003) posits that ethnic and class disadvantages translate from childhood into adulthood, affecting health in later life. Cumulative disadvantage effects over the life course were found in the American (Shuey \& Wilson, 2008; Landes, Ardelt, Vaillant \& Waldinger, 2014; Umberson et al., 2014) and European context (Arber, Fenn \& Meadows, 2014). According to both, the theory of a life-cycle effect and cumulative disadvantage theory, one would expect to find the negative effect of deprivation on health to increase at older ages.

Contrary to this, other research found that age can become a "leveler" (Herd, 2006; Corna, 2013) in that increasing frailty may affect individuals across social strata as they age, thus ameliorating disparities, e.g. by gender and wealth. If age works as a leveler, leading to declining health regardless of disadvantage, we would expect the detrimental health-effects of deprivation to weaken at older ages, as a 'leveling' age-effect gradually takes over. This can be addressed using interactions between age and deprivation.

\section{Area Deprivation and Health}

Because Northern Ireland is largely a rural society, area remoteness and proximity to services are important factors when studying deprivation and its health-implications for older people. According to NISRA, 80\% of Northern Ireland's landmass consists of rural areas with settlements of less than 4,500 inhabitants (NISRA 2005). Approximately $32 \%$ of the population of Northern Ireland live in rural areas, $10 \%$ live in small towns and intermediate settlements and 58\% live in urban areas (Pateman, 2011, p. 20).

A sizeable body of international literature focuses on rurality, deprivation and health, most of it operating with the concept of successful/healthy ageing (Jensen \& Mclaughlin, 1997; McLaughlin \& Jensen, 2000; Glasgow, 2004, p. 277). Glasgow summarizes work on effects of deprivation, social integration, and life course events on health and concludes that 
multilevel analyses that integrate both individual- and aggregate-level relationships and the interplay between them in one modeling framework are lacking (Glasgow, 2004).

Research in the US found the problem of more persistent poverty among older people to be particularly significant in rural areas (Glasgow \& Brown, 1998; Jensen \& Mclaughlin, 1997; McLaughlin \& Jensen, 2000) and some inner city neighborhoods of large metropolitan areas. Somewhat similar patterns have been reported for Great Britain. Gilbert, Philip and Shucksmith (2006) found income deprivation to be more prevalent in remote rural and in urban areas than in intermediate-size settlements. Some epidemiological studies found different effects of rurality on health, but mostly without relating these findings to contexts of deprivation. An American study found the populations of remote areas to be significantly less healthy than the populations of metropolitan areas (Wallace, Grindeanu, \& Cirillo, 2004), and found higher morbidity in general across rural areas of the US.

Area-level deprivation was found to be an important predictor of wellbeing and health over and above individual-level deprivation (Ross \& Mirowsky, 2001; Browning \& Cagney, 2003; Bécares et al., 2012). Not only does being deprived of resources matter, but the mere fact of being surrounded by others who suffer deprivation may lead to social comparison effects affecting an individual's wellbeing and health (Ross \& Mirowsky, 2001; Åberg , Fritzell, Lundberg, Diderichsen, \& Burström, 2003). More importantly, infrastructures and social services in deprived areas are often lacking or inadequate. Structural inadequacies of deprived areas likely affect the well-being and health of older residents, especially of those who already suffer from individual-level material deprivation (Wilson, 2012). Thus far, associations between arealevel income deprivation and health have been analyzed for only one time-point, mostly using aggregate descriptors (Walsh, O’Shea, Scharf, \& Murray, 2012). No previous studies have been conducted on the dynamic interplay between area-level and individual-level deprivation in Northern Ireland over time or on relationships between moving between areas that have different levels of deprivation and the health of older people. 


\section{Strategy}

The analysis has a three-fold objective: First, we describe associations between several measures of individual, household, and Super Output Area (SOA)-level deprivation and the self-reported health of Northern Ireland's older population. Secondly, we analyze relationships between deprivation and the respondents' general health at one time-point, as self-reported on the Census 2011 questionnaire. The analysis will pay particular attention to differences by gender and age. Thirdly, we look at dynamics of change in individual-level material wealth (property value of the respondents' house and access to a car), movement between less-deprived and more-deprived SOA's and the relationships with change in selfreported health between 2001 and 2011.

We try to answer the following research questions: 1 . How are educational-, material(transport-, and low property value), and tenure-deprivation of older people in Northern Ireland related to their self-reported health? 2. Do relationships between deprivation and health vary by gender and age? 3. Does area-deprivation as a contextual effect aggravate the effects of individual deprivation on older people's health? 4. Is change in deprivation over time between 2001 and 2011, such as losing access to a car, a decline in the monetary value of the accommodation people live in and migration from less income-deprived into more income-deprived areas associated with a decline in self-reported health?

Data

The analysis uses data from the Northern Ireland Longitudinal Study (NILS). The NILS is a sample representative of the population of Northern Ireland and is comprised of approximately $28 \%$ of the population of Northern Ireland. The sample was drawn based on 104 birthdates from records from the Northern Ireland Health Card Registration system (NIHCR) (Johnston, Rosato, \& Catney, 2010, pp. 5-6; O’Reilly, Rosato, Catney, Johnston, \& Brolly, 2011). All individuals living in Northern Ireland, who were registered in the Northern 
Ireland Health Card registration system between 2001 and 2011 and have one of the 104 birthdates, are NILS members (Johnston et al., 2010; O’Reilly et al., 2011). The NILS had 105,684 members aged 55 years and older in 2001. 68,385 respondents were enumerated in both the NILS 2001- and 2011. Thus, the sample attrition rate was 35\%. The analysis includes all NILS members, who were 55 years and older in 2001 and subsequently 65 years and older in 2011, have a link to both the 2001- and 2011 Censuses and do not live in a care-home ${ }^{1}$. Of the 68,385 NILS members who were enumerated in both waves, 3,742 observations had missing information on the property-value in 2001 and 2011. These cases were excluded from the analysis. The sample of the analysis is thus $\mathrm{N}=61,773$ respondents.

\section{Methods}

The first step of the analysis is a descriptive comparison of aggregate- and individuallevel percentages of indicators of deprivation and self-reported health to obtain an overview over general patterns across the population. Secondly, in order to analyze relationships between deprivation and self-reported health at one time-point (2011), we perform hierarchical linear modeling (Hox, 2010) of the respondents' self-reported health (five-point scale, $5=$ very good, $1=$ very bad) as reported on the 2011 Census form on several indicators of deprivation and on migration of older people between areas of varying levels of incomedeprivation. The multilevel approach was chosen because the respondents are regionally clustered in areas. Contextual effects of the percentage of income deprived in the respondents' area of residence and area-remoteness (proximity to services) are of substantial interest to this study.

Thirdly, to analyze relationships between change in deprivation and change in health from 2001 to 2011, we computed a binary response variable, 'having experienced a health-

\footnotetext{
${ }^{1}$ We decided to exclude the 2,870 individuals who live in care homes in order to avoid institutionalization bias and because the interest of this paper is in the health of older people living in the community and its relationship with individual- and area-level deprivation.
} 
decline from 2001 to 2011' ( 1 = worse health in 2011 than in 2001, $0=$ health unchanged or increased). The somewhat crude measurement of change in health through a binary variable is due to the fact that, unfortunately, self-reported health was changed from a three-point scale in 2001 to a five-point scale in 2011. Thus, the two scales are not directly comparable. In order to enable a comparison between 2001 and 2011, the 2011-scale had to be recoded into a three-point scale.

The area-level of the multilevel models consists of 890 Super Output Areas (SOA) (NISRA, 2013). SOA are small-area geographies created by the UK's Office for National Statistics (ONS) and NISRA and are based on Output Areas (OA's) and electoral Wards (NISRA, 2013). An SOA has on average 700 households (NISRA 2013, 6). Northern Ireland has 891 SOAs. One sparsely populated SOA had to be dropped from the analysis because no older people live there ${ }^{2}$.

Independent V ariables

Educational deprivation is a household-level variable from the 2011 Census provided by NISRA and coded as follows: the household is educationally deprived if no person aged 18 or older has high school level (level-2) education and no person aged 16-18 is in full-time education or has high school level education. Our measure of transport deprivation is having no access to a car. This is a household level variable and captures all respondents with no car in the household. In many parts of rural Northern Ireland the provision of public transport was found to be limited and insufficient for the needs of older people (Ahern \& Hine, 2012; Heenan, 2010), hence the majority of rural elders largely depend on the car for their transport needs. In rural areas with insufficient public transport it is particularly the income-deprived, who do not have access to a car (Gray, Farrington, Shaw, Martin, \& Roberts, 2001; Power, 2012). To capture change in transport-deprivation, we computed a variable 'loss of access to a

\footnotetext{
${ }^{2}$ Due to NISRA disclosure policy the SOA cannot be identified here.
} 
car 2001-11' ( $1=$ had a car in 2001, but not in $2011,0=$ no change in access to a car).

In order to capture deprivation on the housing (tenure)-dimension, the models include dummies for living in rented social housing and living in privately rented accommodation versus being the owner-occupier (left out as the reference category).

The value of the property the respondents live in in 2011 is in $f$ Sterling and was used as an indicator of relative wealth. The property value data is based on house prices in 2005, is held by NILS-RSU as a data-linkage to the NILS and was obtained from the Land and Property Services (LPS) of Northern Ireland, a division of the Department of Finance and Personnel (NILS-CORE , 2015). For both people who rent and owner occupiers, this is a measure of the quality of housing they can afford. The second model with health-decline as the response includes change in the value of the property between 2001 and 2011. Thus we pick up whether individuals have moved into higher- or lower-priced housing.

Because prior literature suggests that the effect of deprivation can vary by gender and age, the models include gender $(1=$ female, $0=$ male $)$ and age and we also ran models including interactions between gender, age and deprivation measures.

On the SOA-level, we use the aggregate percentage of income-deprived ${ }^{3}$ among the population in 2001 and 2011, and for those who moved between SOA's the change in the SOA-percentage of income-deprived over time (2001-11) (NISRA, 2010) was computed. Thus, the analysis picks up whether respondents moved into more or less deprived areas and whether this is related to a decline in self-reported health (2001-11).

The income-deprived tend to cluster in income deprived areas. Thus, including aggregate-level income deprivation alongside educational, transport and housing deprivation (tenure and property value) gives us a broad (albeit still incomplete) picture of the levels of deprivation of older people in Northern Ireland, and some indication of change over time.

\footnotetext{
${ }^{3}$ The variable captures the percentage of the population living in households in receipt of income support, state pension credit, jobseeker's allowance, or housing benefit per SOA (NISRA 2010).
} 
The models control for marital status (married is the reference category) and whether the respondent lives with younger relatives in the household (at least one person other than the spouse and younger than 65 years).

A general problem when modeling health outcomes is selection bias. In order to adjust for the fact that the respondent may have suffered ill health prior to our measurement of deprivation, the models control for having a limiting long-term illness. Table 1 contains the summary statistics of all variables of the analysis.

The analysis includes two measures of rurality: Firstly, Proximity to Services in 2011 is an indicator of area remoteness and is measured as drive-hours by car to service providers such as GP practices, dentists, post offices and supermarkets (NISRA 2010, 17). High values indicate remote areas and low values areas that are close to services. Both the percentage of income-deprived and Proximity to Services are Census-derived variables provided by NISRA. Our second measure of rurality is an urban-intermediate-rural classification based on settlement bands defined by NISRA $(2005$, p. 3). This measure is commonly used by government departments and is comparable to other parts of the UK (NISRA 2005, 7). The rural-intermediate-urban classification operationalizes towns and cities of 10,000 or more inhabitants as urban; small towns of less than 10,000 inhabitants and settlements of more than 2,250 inhabitants as intermediate settlements; and villages and hamlets of 2,250 and fewer inhabitants as rural (NISRA 2005, 7). Including both measures enables us to capture rural-urban differences in older people's health, as well as the role of access to services on a more fine-grained continuous scale. Since some rural areas are more remote than others, it is important to include both. All variables of the analysis were tested for multicollinearity.

[Table 1 about here] 


\section{Results}

On the Census day 2011, 55\% of our sample were 65 to 74 years old, 33\% were aged 75 to $84,12 \%$ were aged 85 years or older. Regarding individual-level deprivation, $55 \%$ of older NILS members qualify by NISRA's measure as educationally deprived. A quarter of the overall older population, $16 \%$ of those living in rural areas, $24 \%$ of those living in intermediate, and 32\% of those living in urban areas did not have access to a car in 2011 (Table 2). Regarding tenure, $77.8 \%$ are owner-occupiers, $13.4 \%$ live in socially rented housing, and $4.4 \%$ in privately rented housing and $4 \%$ live rent-free (mostly with relatives).

The average house value in Northern Ireland in 2014 was $£, 137,000$. To get an overview, we computed quartiles of the property-value of the respondents' accommodation: $25 \%$ of the older population live in houses worth $f, 67,500$ or less, another $25 \%$ live in housing worth $£^{67,500}$ to $£, 90,000,25 \%$ live in housing worth $£, 90,000$ to $£, 115,000$ and the top $25 \%$ live in housing worth more than $£ 115,000.78 \%$ experienced no change in the value of their property between 2001 and 2011, while 16\% experienced an increase, and 7\% a decrease in property value.

Regarding area-level deprivation, $25 \%$ of the respondents live in the least deprived SOA's where only $8 \%$ of the population are income-deprived; $25 \%$ of older NILS members live in areas where $29 \%$ or more of the population are income-deprived and 10\% live in SOA's where $40 \%$ or more of the residents are income-deprived.

Northern Ireland's older population is not very residentially mobile: only $14.5 \%$ of NILS members aged 65 or older moved from one SOA to another between 2001 and 2011. Of those who moved, $51 \%$ moved to a less income-deprived SOA, $42 \%$ moved to a more income-deprived SOA, while 7\% moved into an SOA with the same level of incomedeprivation as the SOA they lived in 2001.

The percentage of respondents living in social housing (17.6\%) in urban areas is more than twice that of rural areas $(7 \%)$. Private renting is more prevalent in intermediate than 
urban and rural areas. The large majority, $78 \%$ of the population are owner-occupiers, especially in rural areas, where they comprise $83 \%$.

[Table 2 about here]

Table 2 shows the percentages of respondents who experienced ill-health in 2011 and the percentages of those who reported a change in their health between 2001 and 2011.

The dependent variable shows considerable differences in self-reported health between the more and the less deprived elders. Across all deprivation measures the more deprived report significantly worse health than the less-deprived. We find only modest differences between the more- and less-deprived with regards to change in health between 2001 and 2011. The finding might be biased by the fact that health in 2001 was a three-point scale, while health in 2011 was a five-point scale and had to be recoded into a three-point scale to enable comparisons with health in 2001. This may have affected the precision of this measure.

Moving on to the first multilevel model (Table 3) we now address research questions 1 (how are educational-, material, and tenure -deprivation of older people in Northern Ireland related to their self-reported health?) and 2 (Do relationships between deprivation and health vary by gender and age?). In a third step, we address research question 3 by looking at micro-macro relations between (aggregated) area-level deprivation and individual-level deprivation in their effect on self-reported health. This is done via cross-level interactions.

Table 3 shows the results of both models, the first two columns on the left show the coefficients and standard errors of the model with self-reported health in 2011 as the dependent variable (M1), and the two columns on the right show the coefficients (log-odds) of the model with 'health-decline 2001-11' as the dependent variable (M2). The models include all controls as described underneath the Table.

[Table 3 about here] It can be seen from M1 that all deprivation indicators of the analysis are statistically 
significantly negatively related to self-reported health. People with low education, those without access to a car and those living in accommodation that they do not own (social housing and private renting) experience worse health than older people who do not suffer from educational, transport or housing deprivation. Older people and women are subjectively less healthy than younger people and men. Living with younger relatives in one household is significantly negatively related to good health. This could be a selection effect, as oftentimes older people move in with younger relatives when their health declines to avoid living in a care-home.

In order to address differences in the effects of deprivation on self-reported health by gender and age (research question 2), interactions between gender and the deprivation measures, and between age and the deprivation measures were modeled (Table 4).

[Table 4 about here]

Table 4 contains the interaction terms with Wald-tests for self-reported health as the dependent variable. We can see from Table 4 that all interactions with gender, except property-value and area-level income deprivation are statistically significant and negative, indicating that almost all dimensions of deprivation affect men worse than women. Figure 1 visualizes the interactions between gender, tenure, employment and transport deprivation.

[Figure 1 about here]

The bar charts in Figure 1 show that although deprivation is negatively related to health for both genders, the health-difference between the deprived and the not deprived is greater for men. Looking at tenure, among homeowner-occupiers men have slightly better health than women. The average health of both genders is considerably worse if they do not own their accommodation. But among private renters and social renters it is now the women who have the better health. The difference is modest, but statistically significant. A similar health difference between men and women is found for access to a car and unemployment. Looking at long-term unemployment, both men and women report considerably poorer health if they 
experienced long-term unemployment, but the health difference between those who have worked and those who never worked is much larger for men than for women and the gender difference is statistically significant. The models control for limiting long-term illness to avoid self-selection bias.

Looking at age-effects (Table 4), we observe that all interactions between age and individual-level deprivation are statistically significantly negative. However, effect sizes are small and do not indicate a cumulative effect of deprivation on health over the life-course. They merely indicate that the effect of deprivation on health is surpassed by an age effect, rendering both the deprived and the not deprived similarly unhealthy at very old ages: As people age, both the deprived and the not deprived report worse health. We have visualized these interactions using line-charts (not displayed here), which can be obtained from the authors. The only positive interaction between age and deprivation is with area-level income deprivation. The interaction is strongly positive and significant, indicating a cumulative effect of area-deprivation on age-related health-deterioration: Older people living in deprived areas are significantly worse off as they age than older people living in wealthier areas.

We move on to research question 3, focusing on area-level deprivation. The intra-class correlation (ICC) of 0.006 of the full model in Table 3 indicates that including SOA-level income-deprivation does an excellent job of reducing the amount of unexplained variance in overall health that is due to the area-level. The Null-model had an ICC of 0.080 .

The cross-level interactions (Table 4) between SOA-level income deprivation and educational deprivation, having no access to a car, and the tenure variables social housing and living in privately rented accommodation are all statistically significant, indicating a strong context effect of area-level income deprivation. Figure 2 visualizes the cross-level interactions between having no access to a car, tenure, property- value and the percentage of income deprived per SOA.

[Figure 2 about here] 
The negative statistical effects of being transport- and housing-deprived on the self-reported health of older people become stronger the more deprived the SOA of residence is. The effect is particularly strong with regard to housing deprivation: all groups whether deprived or not report worse health the more deprived their area of residence is, but the context effect is stronger for those who do not own their accommodation and those living in housing that has a lower market value. Thus, research question 3 can be answered in the affirmative: Area-level income deprivation significantly worsens the already adverse effects of individual-level deprivation on subjective health.

The analysis now moves on to research question 4 , to check whether deprivation, in particular moving into cheaper housing and more deprived areas, is not only related to worse self-reported health of older people, but also to a decline in health in a ten-year span.

The columns on the right of Table 3 (M2) contain the coefficients and standard errors of the binary logistic multilevel model with 'health decline 2001-11' as the dependent variable. The model includes indicators of change in deprivation: whether the respondents have lost access to a car between 2001 and 2011, the change in the value of the property in which the respondents live (2001-11) and the change in the level of income deprivation of the respondents' SOA (2001-11). M2 includes all controls as described below the Table. The model shows that experiencing a decline in property value, either through moving into cheaper accommodation or through a decline in the worth of the property the respondent lives in, is statistically significantly related to having declining health. Furthermore, an increase in the percentage of income-deprived in the respondent's area of residence is associated with a statistically significant decline in their health. Research question 4 can thus be answered: both moving into cheaper housing and into more deprived areas is related to worse health and to a health decline.

The other deprivation indicators also show the expected relationships; older people who have lost access to a car (2001-11), are educationally deprived, moved into lower-valued 
housing, have never worked and who do not own their accommodation are all more likely to experience a health-decline between 2001 and 2011.

\section{Discussion}

The analysis of the NILS data found considerable deprivation among Northern Ireland's older population. A quarter of the overall and 16\% of the rural population of elderly have no access to a car, and more than $10 \%$ live in social housing. Also, a quarter of Northern Ireland's older population live in SOAs in which at least a third of the residents are incomedeprived, and 10\% live in SOAs with more than $40 \%$ of the population income-deprived.

This paper tried to answer four research questions: 1 . How are educational-, material(transport-, and low property value), and tenure-deprivation of older people in Northern Ireland related to their self-reported health? 2. Do relationships between deprivation and health vary by gender and age? 3. Does area-deprivation as a contextual factor aggravate the effects of individual- and household-level deprivation on older people's health? 4. Is change in deprivation between 2001 and 2011, such as giving up the car, a decline in the monetary value of the accommodation people live in and moving into more income-deprived areas associated with a decline in self-reported health? In order to answer these research questions, we fitted multilevel models of the respondent's self-reported health and decline in health (2001-2011) on individual- and area-level deprivation.

The results of the multilevel analyses show that all dimensions of deprivation that are measured in the NILS (education-, employment, transport, housing, and area-level income deprivation) are statistically significantly related to worse self-reported health and a decline in health within a ten-year time-span.

The analysis yielded interesting differences by gender: Deprivation is strongly related to health-disadvantage for both genders, but the negative effect on self-reported health is stronger for men than for women, especially when it comes to home ownership, access to a car and long-term unemployment. The findings make sense in light of gender role 
expectations. Conservative gender-roles, such as the man being the bread-winner and active partner who drives the car are still prevalent among the older generation in Northern Ireland. Thus, in addition to its material consequences, deprivation may also undermine older men's sense of self-worth, as they struggle (with the inability) to fulfill traditional gender-norms with which they were brought up. Our findings support the theory that gender-roles affect health (Bird \& Rieker 1999, Courtenay 2000) and concur with studies that found deprivation to be detrimental to self-perceived health especially of men (Arber et al., 2014, Adena \& Myck 2014). However, Northern Ireland is a specific context with a known prevalence of traditional gender roles among the older generation. Deprivation and gender may interact differently in less traditional contexts.

The results of the interactions between deprivation and age indicate that old age does indeed seem to level effects of deprivation, as described in some of the literature (Herd 2006, Corna 2013). In our sample of respondents who were 55 years and older in 2001, the health difference between the deprived and the more affluent diminishes with increasing age, as health deteriorates across all social strata. Given the high attrition rate of the sample, it has to be noted, however, that the observed pattern of age as a leveller could be largely due to selective mortality, as the deprived are more likely to suffer a premature death. Thus, our result does not contradict cumulative disadvantage theory. Even without assuming a presence of selective mortality, however, a cumulative disadvantage mechanism may well be at work at younger ages, as was found in much of the literature (Lands et al., 2014, Arber et al.; Arber et al., 2014). More information on the respondents' socio-economic status at younger ages, preferably going back to childhood and analyses of data on premature mortality would be needed to be able to test this theory for the Northern Irish context.

Regarding the contextual level, we found strong moderation of the statistical effects of individual-level deprivation by area-deprivation. The cross-level interactions show an area-a level effect of deprivation over and above individual-level deprivation. The main effect of 
area-level income-deprivation already showed that everybody, regardless of their individual levels of deprivation, is less likely to experience good health, if they live in deprived areas. However, the contextual effect is stronger for those who already suffer deprivation on the individual level. Those who suffer socio-economic deprivation are already worse off with regards to their self-reported health, but, if they live in income-deprived areas, this context aggravates the effect of individual deprivation. The contextual deprivation effect is known from literature on other countries (Atkinson \& Kintrea, 2001; Browning \& Cagney, 2003; Stafford \& Marmot, 2003), but it had not been analyzed for older people and for the Northern Irish context yet. Our multilevel models demonstrated the same strong relationships and context effects associated with a decline in self-reported health over time (2001-2011). The findings thus reveal clear patterns of relationships between socio-economic deprivation and self-reported ill-health of older people, both at one time-point and over a tenyear time-span. The findings are based on an exceptionally large, high quality Census-linked sample of older people in Northern Ireland and can thus claim representativeness for Northern Ireland's older population.

The scope of this paper is constrained by the following limitations: The sample design is restricted to cohorts aged 55 and older in 2001, thus our study cannot trace the potential cumulative effect of disadvantage at younger ages. Furthermore, sample attrition due to mortality may have led to a selection effect (Markides \& Machalek 1984, Herd 2006), as we cannot trace those who dropped out due to death. This may have led to an under-estimation of deprivation effects on health. The analysis of deprivation is restricted by the measures available in the NILS. The NILS does not contain an individual- or household-level measure of income and does not have measures of cultural capital and cultural consumption. Unfortunately, the scale of self-reported health was changed from 2001 to 2011 from a threeto a five-point scale. To allow for comparisons over time the scale had to be recoded back into a three-point scale, which likely affected its precision. 
Another limitation is the fact that the study is based on only two time-points and the ten-year span between the two Censuses. Our analysis could not pick up effects of events that happened between the two time-points. This study could thus only give a contemporary snapshot of how deprivation affects older people's mental health between the two Censuses 2001 and 2011. Future studies of more waves of data, also enabling comparisons within and between cohorts would add greatly to the existing body of knowledge.

Notwithstanding these limitations, our analysis showed clear and robust patterns of health-disadvantage of older people suffering deprivation on the individual-, household-, and SOA-area-levels, which was captured by a multitude of deprivation measures.

\section{Conclusions}

This article presented results of a Census-linked study with an exceptionally large sample of older people -- representative of a whole population of elders aged 65 plus. Our findings have policy-relevance, pointing towards an obvious need to address the problem of deprivation of older people in Northern Ireland. Deprivation of individuals and residential areas is an important factor impairing the health of a large share of Northern Ireland's older population. Developing policies ameliorating effects of area-level income, transport, and tenure-deprivation is an important current task for policy-makers. Improving institutional support structures of deprived areas can significantly improve health outcomes for older people. 


\section{References}

Åberg Yngwe, M., Fritzell, J., Lundberg, O., Diderichsen, F., \& Burström, B. (2003). Exploring relative deprivation: Is social comparison a mechanism in the relation between income and health? Social Science \& Medicine, 57(8), 1463-1473. http://doi.org/10.1016/S02779536(02)00541-5

Adena, M., \& Myck, M. (2014). Poverty and transitions in health in later life. Social Science \& Medicine, 116, 202-210. http://doi.org/10.1016/j.socscimed.2014.06.045

Ahern, A., \& Hine, J. (2012). Rural transport - Valuing the mobility of older people. Research in Transportation Economics, 34(1), 27-34. http://doi.org/10.1016/j.retrec.2011.12.004

Arber, S., Fenn, K., \& Meadows, R. (2014). Subjective financial well-being, income and health inequalities in mid and later life in Britain. Social Science \& Medicine, 100, 12-20. http://doi.org/10.1016/j.socscimed.2013.10.016

Arber, S., \& Ginn, J. (1993). Gender and inequalities in health in later life. Social Science \& Medicine, 36(1), 33-46. http://doi.org/10.1016/0277-9536(93)90303-L

Atkinson, R., \& Kintrea, K. (2001). Disentangling area effects: evidence from deprived and nondeprived neighbourhoods. Urban Studies, 38(12), 2277-2298. http://doi.org/10.1080/00420980120087162

Bécares, L., Nazroo, J., Albor, C., Chandola, T., \& Stafford, M. (2012). Examining the differential association between self-rated health and area deprivation among white British and ethnic minority people in England. Social Science \& Medicine, 74(4), 616-624. http://doi.org/10.1016/j.socscimed.2011.11.007

Bird, C. E., \& Rieker, P.P. (1999). “Gender matters: An integrated model for understanding men's and women's health.” Social Science \& Medicine 48 (6): 745-55. doi:10.1016/S0277-9536(98)00402$\mathrm{X}$.

Browning, C. R., \& Cagney, K. A. (2003). Moving beyond poverty: Neighborhood structure, social processes, and health. Journal of Health and Social Behavior, 44(4), 552-571. http://doi.org/10.2307/1519799

Callan, T., Nolan, B., \& Whelan, C. T. (1993). Resources, deprivation and the measurement of 
poverty. Journal of Social Policy, 22(02), 141-172. http://doi.org/10.1017/S0047279400019280

Champion, T., \& Shepherd, J. (2006). Demographic change in rural England. In The Ageing Countryside. The Growing Older Population of Rural England (pp. 29-50). London.

Corna, L. M. (2013). “A life course perspective on socioeconomic inequalities in health: A critical review of conceptual frameworks." Advances in Life Course Research 18 (2): 150-59. doi:10.1016/j.alcr.2013.01.002.

Courtenay, W. H. (2000). “Constructions of masculinity and their influence on men's well-being: A theory of gender and health.” Social Science \& Medicine 50 (10): 1385-1401. doi:10.1016/S02779536(99)00390-1.

Crimmins, E.M., Kim, J. \& Solé-Auró, A. (2011). Gender differences in health: results from SHARE, ELSA and HRS. The European Journal of Public Health, 21(1), pp.81-91.

Dannefer, D. (2003). “Cumulative advantage/disadvantage and the life course: Cross-Fertilizing age and social science theory." The Journals of Gerontology Series B: Psychological Sciences and Social Sciences 58 (6): S327-37. doi:10.1093/geronb/58.6.S327.

Denton, M., Prus, S., \& Walters, V. (2004). "Gender differences in health: A Canadian study of the psychosocial, structural and behavioural determinants of health." Social Science $\approx$ Medicine 58 (12): 2585-2600. doi:10.1016/j.socscimed.2003.09.008.

Gilbert, A., Philip, L., \& Shucksmith, M. (2006). Rich and poor in the countryside. In P. Lowe \& L. Speakman (Eds.), The Ageing Countryside. The Growing Older Opulation of Rural England. London: Age Concern.

Glasgow, N. (2004). Healthy aging in rural America. In N. Glasgow, L.W. Morton, \& N. E. Johnson (Eds.), Critical Issues in Rural Health (pp. 271-281). Ames: Blackwell Publishers Ltd.

Glasgow, N., \& Brown, D. L. (1998). Older, rural, and poor. In R. T. Coward \& J. A. Krout (Eds.), Aging in Rural Settings. New York: Springer.

Glasgow, N., Holden, K. C., McLaughlin, D.K. \& Rowles, G. (1993). The rural elderly and poverty. In The Rural Sociological Society Task Force on Persistent Rural Poverty (Ed.), Persistent Poverty in Rural America. San Francisco, CA, US: Westview Press,.

Gray, D., Farrington, J., Shaw, J., Martin, S., \& Roberts, D. (2001). Car dependence in rural Scotland: 
Transport policy, devolution and the impact of the fuel duty escalator. Journal of Rural Studies, 17(1), 113-125. http://doi.org/10.1016/S0743-0167(00)00035-8

Groffen, D. A. I., Bosma, H., van den Akker, M., Kempen, G. I. J. M., \& van Eijk, J. T. M. (2008). Material deprivation and health-related dysfunction in older Dutch people: findings from the SMILE study. The European Journal of Public Health, 18(3), 258-263.

http://doi.org/10.1093/eurpub/ckm119

Heenan, D. (2010). Rural Ageing in Northern Ireland: Quality of Life amongst Older People. Belfast: Office of the First Minister and Deputy First Minister.

Herd, P. (2006). "Do functional health inequalities decrease in old age? Educational status and functional decline among the 1931-1941 Birth Cohort." Research on Aging 28 (3): 375-92. doi:10.1177/0164027505285845.

Hox, J. J. (2010). Multilevel Analysis: Techniques and Applications. Routledge.

Idler, E.L., (2003). "Discussion: Gender differences in self-rated health, in mortality, and in the relationship between the two." The Gerontologist, 43(3), pp.372-375.

Jensen, L., \& Mclaughlin, D. K. (1997). The escape from poverty among rural and urban elders”. The Gerontologist, 37(4), 462-468. http://doi.org/10.1093/geront/37.4.462.

Johnston, F., Rosato, M., \& Catney, G. (2010). The Northern Ireland Longitudinal Study - An Introduction. NILS Working Paper 1.0 (pp. 1-17). Belfast: NILS Research Support Unit.

Landes, S.D., Ardelt, M., Vaillant, G.E. \& Waldinger, R. J. (2014). “Childhood adversity, midlife generativity, and later life well-being." The Journals of Gerontology Series B: Psychological Sciences and Social Sciences, May, gbu055. doi:10.1093/geronb/gbu055.

Lang, I. A., Hubbard, R. E., Andrew, M. K., Llewellyn, D. J., Melzer, D., \& Rockwood, K. (2009). "Neighborhood deprivation, individual socioeconomic status, and frailty in older adults." Journal of the American Geriatrics Society, 57(10), 1776-1780. http://doi.org/10.1111/j.15325415.2009.02480.x.

Lowe, P., \& Speakman, L. (2006). “The greying countryside.” In The Ageing Countryside. The Growing Older Population of Rural England (pp. 9-28). London: Age Concern.

MacInnes, T., Aldgridge, H., Parekh, A., \& Kenway, P. (2012). Monitoring Poverty and Social Exclusion in 
Northern Ireland 2012 (pp. 1-54). York: Joseph Rowntree Foundation. Retrieved from http://www.jrf.org.uk/publications/monitoring-poverty-northern-ireland-2012

MacInnes, T., Aldridge, H., Bushe, S., Tinson, A., \& Born, T. (2014). Monitoring Poverty and Social Exclusion 2014. York: Joseph Rowntree Foundation and The New Policy Institute.

Markides, K.S., and Machalek, R. (1984). "Selective survival, aging and society." Archives of Gerontology and Geriatrics 3 (3): 207-22. doi:10.1016/0167-4943(84)90022-0.

McDonough, P. \& Walters, V. (2001). Gender and health: Reassessing patterns and explanations. Social Science \& Medicine, 52(4), pp.547-559.

McGill, P. (2014). Understanding Socio-economic Inequalities affecting Older People. Northern Ireland: Centre for Ageing and Development (CARDI). Retrieved from http://www.cardi.ie/

publications/understandingsocioeconomicinequalitiesaffectingolderpeople

McLaughlin, D. K., \& Jensen, L. (2000). “Work history and U.S. elders' transitions into poverty.” The Gerontologist, 40(4), 469-479. http://doi.org/10.1093/geront/40.4.469

NILS-CORE, 2015. NILS Database Metadata, Belfast: Northern Ireland Statistics and Research Agency

NISRA. (2005). Report on the Inter-Departmental Urban-Rural definition Group. Statistical Clarification ad Delineation of Settlements. Belfast: Northern Ireland Statistics and Research Agency (NISRA).

NISRA. (2010). Northern Ireland Multiple Deprivation Measure 2010. Belfast: Northern Ireland Statistics and Research Agency (NISRA).

NISRA. (2013). Super Output Areas for Northern Ireland. Modifications for 2001 Super output Areas for the 2011 Census Data. Belfast.

Nolan, B., \& Whelan, C. T. (1996). Resources, Deprivation, and Poverty (OUP Catalogue). Oxford University Press. https://ideas.repec.org/b/oxp/obooks/9780198287858.html

O’Reilly, D., Rosato, M., Catney, G., Johnston, F., \& Brolly, M. (2011). “Cohort description: The Northern Ireland Longitudinal Study (NILS).” International Journal of Epidemiology, dyq271. http://doi.org/10.1093/ije/dyq271

Pateman, T. (2011). Rural and Urban Areas: Comparing Lives using Rural/Urban Classifications. London: Office for National Statistics. Retrieved from www.ons.gov.uk

Payne, R. A., \& Abel, G. A. (2012). "UK indices of multiple deprivation - a way to make comparisons 
across constituent countries easier." Health Statistics Quarterly, 53, 1-16.

Ploubidis, G. B., Benova, L., Grundy, E., Laydon, D., \& DeStavola, B. (2014). “Lifelong socioeconomic position and biomarkers of later life health: Testing the contribution of competing hypotheses." Social Science \& Medicine, 119, 258-265. http://doi.org/10.1016/j.socscimed.2014.02.018

Power, A. (2012). "Social inequality, disadvantaged neighbourhoods and transport deprivation: An assessment of the historical influence of housing policies." Journal of Transport Geography, 21, 39-48. http://doi.org/10.1016/j.jtrangeo.2012.01.016

Ross, C. E., \& Mirowsky, J. (2001). "Neighborhood disadvantage, disorder, and health.” Journal of Health and Social Behavior, 42(3), 258-276. http://doi.org/10.2307/3090214

Scharf, T., \& Bartlam, B. (2008). "Ageing and social exclusion in rural communities.” In N. C. Keating (Ed.), Rural Ageing. A Good Place to Grow Old? (pp. 97-108). Policy Press.

Scharf, T., \& Keating, N. C. (2012a). From Exclusion to Inclusion in Old Age: A Global Challenge. Policy.

Scharf, T., \& Keating, N. C. (2012b). "Social exclusion in later life: A global challenge.” In T. Scharf \& N. C. Keating (Eds.), From Exclusion to Inclusion in Old Age: a Global Challenge (pp. 1-16). Bristol: Policy Press.

Shuey, K. M., \& Willson, A.E. 2008. "Cumulative disadvantage and black-white disparities in lifecourse health trajectories." Research on Aging 30 (2): 200-225. doi:10.1177/0164027507311151.

Stafford, M., \& Marmot, M. (2003). "Neighbourhood deprivation and health: Does it affect us all equally?" International Journal of Epidemiology, 32(3), 357-366. http://doi.org/10.1093/ije/dyg084

Stafford, M., S. Cummins, S. Macintyre, A. Ellaway, \& Marmot, M. (2005). "Gender differences in the associations between health and neighbourhood environment." Social Science \& Medicine 60 (8): 1681-92. doi:10.1016/j.socscimed.2004.08.028.

Townsend, P. (1987). “Deprivation.” Journal of Social Policy, 16(02), 125-146. http://doi.org/10.1017/S0047279400020341.

Umberson, D., Williams, K., Thomas, P.A., Liu, H., \& Thomeer, M.B. (2014). “Race, gender, and chains of disadvantage childhood adversity, social relationships, and health." Journal of Health 
and Social Behavior 55 (1): 20-38. doi:10.1177/0022146514521426.

Verbrugge, Lois M. 1985. “Gender and health: An update on hypotheses and evidence.” Journal of Health and Social Behavior 26 (3): 156-82. doi:10.2307/2136750.

Wallace, R. B., Grindeanu, L. A., \& Cirillo, D. J. (2004). "Rural/urban contrasts in population morbidity status.” In N. Glasgow, L. W. Morton, \& N. E. Johnson (Eds.), Critical Issues in Rural Health (pp. 15-26). Ames: Blackwell.

Walsh, K., O’Shea, E., Scharf, T., \& Murray, M. (2012). “Ageing in changing community contexts: Cross-border perspectives from rural Ireland and Northern Ireland." Journal of Rural Studies, 28(4), 347-357. http://doi.org/10.1016/j.jrurstud.2012.01.012

Walsh, K., Scharf, T., Cullinan, J., \& Finn, C. (2012). Deprivation and its measurement in later life: findings from a mixed-methods study in Ireland (Report). ICSG. Retrieved from http://aran.library.nuigalway.ie/xmlui/handle/10379/3242

Walsh, K., \& Ward, P. (2013). Social Exclusion and Ageing in Rural Areas. Patterns and Implications (No. 3, Rural Ageing Observatory Working Paper). Galway: Irish Centre for Social Gerontology.

Wilson, W. J. (2012). The Truly Disadvantaged: The Inner City, the Underclass, and Public Policy, Second Edition. University of Chicago Press. 
Table 1: Summary Statistics of the Dependent and Independent Variables

\begin{tabular}{|c|c|c|c|c|c|c|}
\hline & Binary Variables: & Obs. & Percent & & Min & Max \\
\hline $\begin{array}{l}\text { Educational } \\
\text { deprivation: }\end{array}$ & Educationally deprived & 65605 & 55.0 & & 0 & 1 \\
\hline \multirow[t]{3}{*}{ Tenure: } & Social housing & 65623 & 13.4 & & 0 & 1 \\
\hline & Private renter & 65623 & 4.1 & & 0 & 1 \\
\hline & Owner-occupier & 65623 & 77.4 & & 0 & 1 \\
\hline $\begin{array}{l}\text { Transport/Material } \\
\text { Deprivation: }\end{array}$ & No access to a car in 2011 & 65623 & 25.4 & & 0 & 1 \\
\hline Gender: & female & 65605 & 56.1 & & 0 & 1 \\
\hline \multirow[t]{3}{*}{$\begin{array}{l}\text { Rural-urban } \\
\text { Differences: }\end{array}$} & Rural & 65623 & 32.2 & & 0 & 1 \\
\hline & Intermediate Settlement & 65623 & 16.0 & & 0 & 1 \\
\hline & Urban & 65623 & 51.7 & & 0 & 1 \\
\hline \multirow[t]{5}{*}{ Marital Status: } & Single & 65606 & 31.1 & & 0 & 1 \\
\hline & Married 2011 & 65623 & 57.2 & & 0 & 1 \\
\hline & Widowed, 2011 & 65623 & 13.3 & & 0 & 1 \\
\hline & Divorced, 2011 & 65623 & 1.3 & & 0 & 1 \\
\hline & Continuous Variables: & Obs. & Mean & $\begin{array}{l}\text { Std. } \\
\text { Dev. }\end{array}$ & Min & Max \\
\hline \multirow[t]{5}{*}{ Healtb: } & $\begin{array}{l}\text { Self-reported Health } 2011 \\
\text { (five-point scale) }\end{array}$ & 65605 & 3.433 & 0.945 & 1 & 5 \\
\hline & $\begin{array}{l}\text { Self-reported Health } 2011 \\
\text { (three-point-scale) }\end{array}$ & 65603 & 1.330 & 0.704 & 0 & 2 \\
\hline & $\begin{array}{l}\text { Self-reported Health } 2001 \\
\text { (three-point-scale) }\end{array}$ & 65603 & 1.268 & 0.763 & 0 & 2 \\
\hline & Change in Health 2001-11 & 65603 & 0.061 & 0.075 & -2 & 2 \\
\hline & Age & 65605 & 74.21 & 7.317 & 65 & $100+$ \\
\hline \multirow[t]{7}{*}{ Property-value } & Property value in 2001 & 60709 & 122,258 & 80,681 & 0 & $1,000000+$ \\
\hline & Property value in 2011 & 61773 & 120,092 & 75,321 & 0 & $1,000000+$ \\
\hline & $\begin{array}{l}\text { Change in Property value } \\
2001-2011\end{array}$ & 58,946 & $132,6.34$ & 331,646 & -1700000 & $1,000000+$ \\
\hline & Macro-level Variables: & $\begin{array}{l}\text { Level- } \\
2 \text { Obs. }\end{array}$ & Mean & $\begin{array}{l}\text { Std. } \\
\text { Dev. }\end{array}$ & Min. & Max. \\
\hline & $\begin{array}{l}\text { Income-deprivation of older } \\
\text { people/ SOA }\end{array}$ & 890 & 0.201 & 0.136 & 0.00 & 0.78 \\
\hline & $\begin{array}{l}\text { Change in Income- } \\
\text { deprivation/ SOA }\end{array}$ & 890 & 0.203 & 0.138 & 0.01 & 0.78 \\
\hline & Proximity to Services/SOA & 890 & 0.000 & 1.000 & -1.17 & 4.18 \\
\hline
\end{tabular}

Note: Income-deprivation per SOA is measured as the proportion of households in receipt of state benefits per SOA. Due to a non-disclosure policy of the data provider in order to eliminate the risk of identifying individual respondents, the exact maximum values for age, property value 0n 2001 and 2011 and change in property value 
cannot be reported here.

Table 2: Self-reported Health by Deprivation, Row-Percentages

\begin{tabular}{|c|c|c|c|c|}
\hline & \multirow{2}{*}{$\begin{array}{c}\text { Ill-Health } \\
2011 \\
\end{array}$} & \multicolumn{3}{|c|}{ Change in Health 2001-11 } \\
\hline & & $\begin{array}{l}\text { Health } \\
\text { Declined }\end{array}$ & $\begin{array}{l}\text { Health } \\
\text { Improved }\end{array}$ & $\begin{array}{l}\text { Health } \\
\text { Unchanged }\end{array}$ \\
\hline & $\%$ & $\%$ & $\%$ & $\%$ \\
\hline Educationally Deprived & 16.79 & 20.4 & 25.9 & 53.6 \\
\hline Not Educationally Deprived & 10.0 & 16.6 & 22.5 & 60.9 \\
\hline No Access to a Car & 20.9 & 22.3 & 26.8 & 50.9 \\
\hline Has Access to a Car & 11.3 & 17.5 & 23.5 & 59.0 \\
\hline Tenure: Owner-occupier & 11.3 & 18.0 & 23.3 & 58.7 \\
\hline Tenure: Private renter & 16.4 & 21.5 & 27.9 & 50.7 \\
\hline Tenure: Social housing & 25.1 & 21.0 & 29.2 & 49.9 \\
\hline \multicolumn{5}{|l|}{ Property-value in 2011: } \\
\hline Lowest quartile & 20.3 & 20.9 & 27.2 & 51.9 \\
\hline $2^{\text {nd }}$ lowest quartile & 17.0 & 20.2 & 26.3 & 53.5 \\
\hline $2^{\text {nd }}$ highest & 11.0 & 18.5 & 23.4 & 58.1 \\
\hline Highest & 6.7 & 15.2 & 64.6 & 20.2 \\
\hline \multicolumn{5}{|c|}{ Area (SOA)-level Income deprivation } \\
\hline \multicolumn{5}{|l|}{ (quartiles): } \\
\hline Least deprived quartile & 8.1 & 16.0 & 22.1 & 61.8 \\
\hline $2^{\text {nd }}$ least deprived quartile & 11.5 & 18.6 & 23.2 & 58.1 \\
\hline $2^{\text {nd }}$ most deprived & 14.3 & 20.0 & 24.7 & 55.3 \\
\hline Most deprived quartile & 21.5 & 20.0 & 27.7 & 52.0 \\
\hline Total & 13.7 & 18.7 & 24.3 & 57.0 \\
\hline
\end{tabular}


Table 3: Multilevel Models - Deprivation, Self-reported Health and Change in Health

\begin{tabular}{|c|c|c|c|c|}
\hline & \multicolumn{2}{|c|}{ M1 - Self-reported Health } & \multicolumn{2}{|c|}{ M2 - Health-decline 2001-11 } \\
\hline & Coef. & S.E. & Coef. & S.E. \\
\hline Age & $-0.014 * * *$ & 0.001 & $0.037 * * *$ & 0.002 \\
\hline Gender: female & $-0.040 * * *$ & 0.007 & $-0.088^{* * *}$ & 0.023 \\
\hline No access to a car & $-0.176^{* * *}$ & 0.01 & . & . \\
\hline Lost access to a car 2001-11 & . & . & $0.303 * * *$ & 0.024 \\
\hline Never worked & $-0.152 * * *$ & 0.013 & $0.133 * * *$ & 0.037 \\
\hline Social housing & $-0.156^{* * *}$ & 0.011 & $0.016^{* *}$ & 0.005 \\
\hline Private renter & $-0.100 * * *$ & 0.018 & $0.144 * *$ & 0.052 \\
\hline Property-value, 2011 & $0.004 * * *$ & 0.000 & . & . \\
\hline Change in Property-value, 2001-11 & & & $-0.001 * * *$ & 0.000 \\
\hline Educational deprivation & $-0.170 * * *$ & 0.008 & $0.158 * * *$ & 0.024 \\
\hline Moved between SOA's & $-0.032 * *$ & 0.01 & $0.073^{*}$ & 0.031 \\
\hline$\%$ Income deprived/SOA & $-0.716^{* * *}$ & 0.034 & . & . \\
\hline Change in \% Income deprived 2001-11 & . & . & $0.358^{* * *}$ & 0.087 \\
\hline Proximity to Services /SOA & -0.009 & 0.009 & 0.017 & 0.009 \\
\hline Constant & $4.821 * * *$ & 0.042 & $-4.390 * * *$ & 0.132 \\
\hline Level-2-Variance, $\sigma^{2}$ & $-2.720 * * *$ & 0.083 & $-2.613 * * *$ & 0.435 \\
\hline Residual-variance & $-0.164 * * *$ & 0.003 & & \\
\hline $\mathrm{N}$ & 61773 & & 61773 & \\
\hline ICC & 0.006 & & 0.019 & \\
\hline
\end{tabular}

Note: M1 reports coefficients and their standard errors of a hierarchical linear multilevel model of the respondents' self-reported health as asked in the Census 2011 on a five-point scale ( $1=$ bad health, $5=$ very good health). M2 reports coefficients and their standard errors of a binary logistic multilevel model of a decline in self reported health (Health-decline: $1=y e s, 0=$ no). The models control for limiting long-term illness, living alone, marital status (divorced, widowed, reference category: married), living in a rural area, living in an intermediate area (reference category: urban area), living with relatives in the household who are of working-age and are not the spouse. 
Table 4: Coefficients and Standard Errors of Interactions

\begin{tabular}{|c|c|c|c|c|}
\hline \multirow[t]{2}{*}{ Interaction: } & \multicolumn{4}{|c|}{ DV: Self-reported Health } \\
\hline & Coef. & S.E. & Wald-test & $\mathrm{df}$ \\
\hline Gender * property-value & 0.001 & 0.000 & 2.14 & 1 \\
\hline Gender * social housing & $-0.068^{* *}$ & 0.021 & $10.78^{* *}$ & 1 \\
\hline Gender * private renter & $-0.116^{* *}$ & 0.036 & $10.7 * *$ & 1 \\
\hline Gender * never worked & $-0.105^{* *}$ & 0.035 & $9.00 * *$ & 1 \\
\hline Gender $*$ no access to a car & $-0.078^{* * *}$ & 0.017 & $21.15^{* * *}$ & 1 \\
\hline Gender* educational deprivation & $-0.028^{* * *}$ & 0.014 & $4.08 *$ & 1 \\
\hline Gender* living alone in the household & $-0.129 * * *$ & 0.016 & $65.00 * * *$ & 1 \\
\hline Gender $* \%$ Income-deprived/SOA & 0.001 & 0.050 & 0.00 & 1 \\
\hline Age*property-value & $0.010^{* * *}$ & 0.000 & $69.6^{* * *}$ & 1 \\
\hline Age* social housing & $-0.014 * * *$ & 0.001 & $112.62 * * *$ & 2 \\
\hline Age $*$ private renter & 0.000 & 0.000 & $27.36 * * *$ & 2 \\
\hline Age* never worked & $-0.006^{* * *}$ & 0.002 & $16.09 * * *$ & 1 \\
\hline Age $*_{\text {no }}$ access to a car & $-0.005^{* * *}$ & 0.001 & $21.33 * * *$ & 1 \\
\hline Age*educational deprivation & $-0.008^{* * *}$ & 0.001 & $73.85^{* * *}$ & 1 \\
\hline Age* \% Income-deprived/SOA & $0.260 * * *$ & 0.066 & $15.6^{* * *}$ & 1 \\
\hline Property-value* \% Income-deprived/SOA & $0.026^{* * *}$ & 0.004 & $33.45^{* * *}$ & 1 \\
\hline Social rent $* \%$ Income-deprived/SOA & $-0.146^{* * *}$ & 0.067 & $4.67 *$ & 1 \\
\hline Private renter $* \%$ Income-deprived/SOA & -0.034 & 0.138 & 0.06 & 1 \\
\hline Never worked $* \%$ Income-deprived/SOA & -0.052 & 0.086 & 0.37 & 1 \\
\hline No car 2011*0\% Income-deprived/SOA & $-0.480 * * *$ & 0.055 & $41.6^{* * *}$ & 1 \\
\hline $\begin{array}{l}\text { Educational deprivation } * \% \text { Income- } \\
\text { deprived/SOA }\end{array}$ & -0.011 & 0.053 & 0.04 & 1 \\
\hline
\end{tabular}

Note: Each interaction was included together with its main effects in the fully controlled model as displayed in Tablev3. 'Social housing' and 'private renter' were included together in the same model, as they form two categories of 'tenure' (owner-occupier is the reference category). 
Figure 1: Interactions between Deprivation and Gender
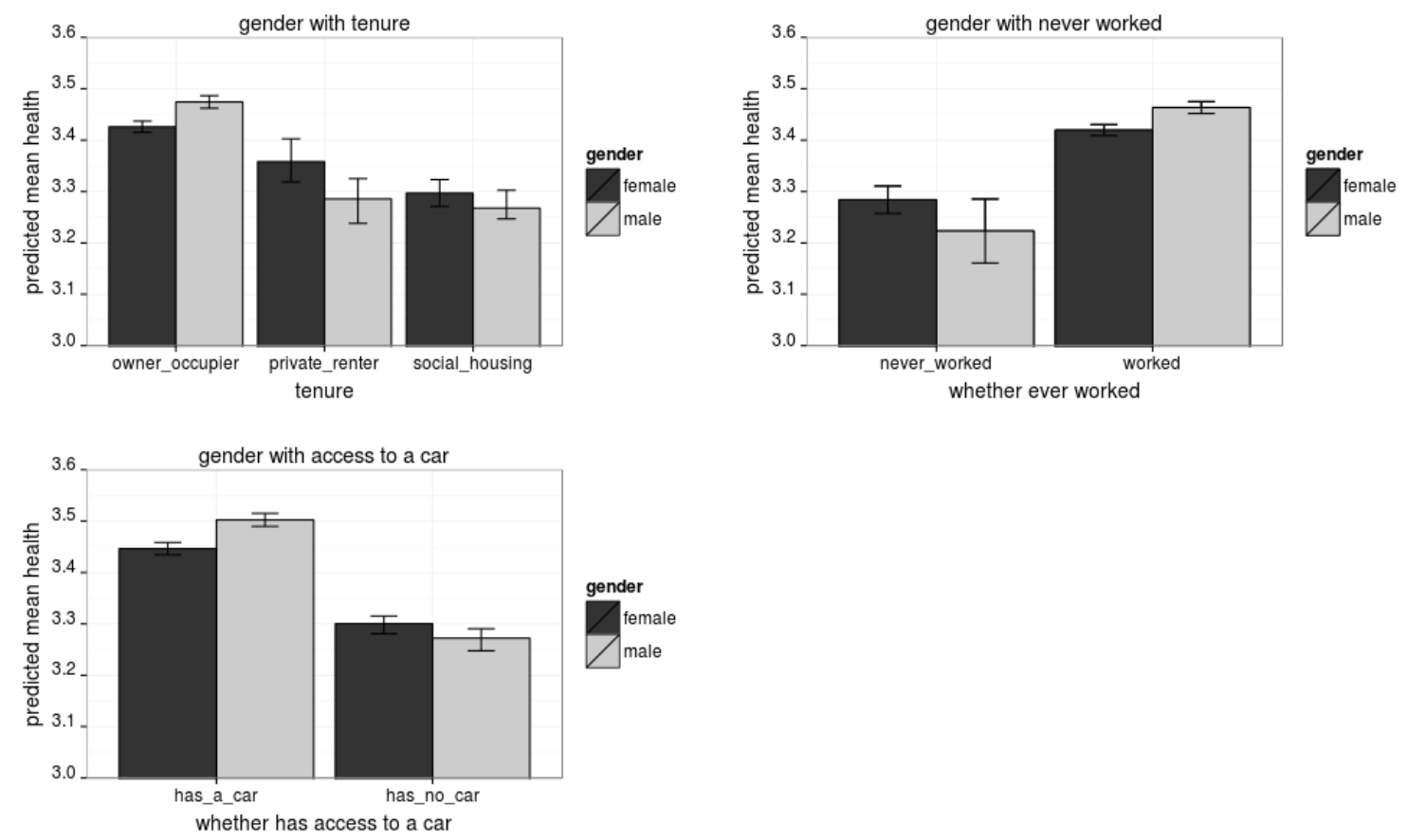

Figure 2: The interplay between Individual-level and Area-Deprivation
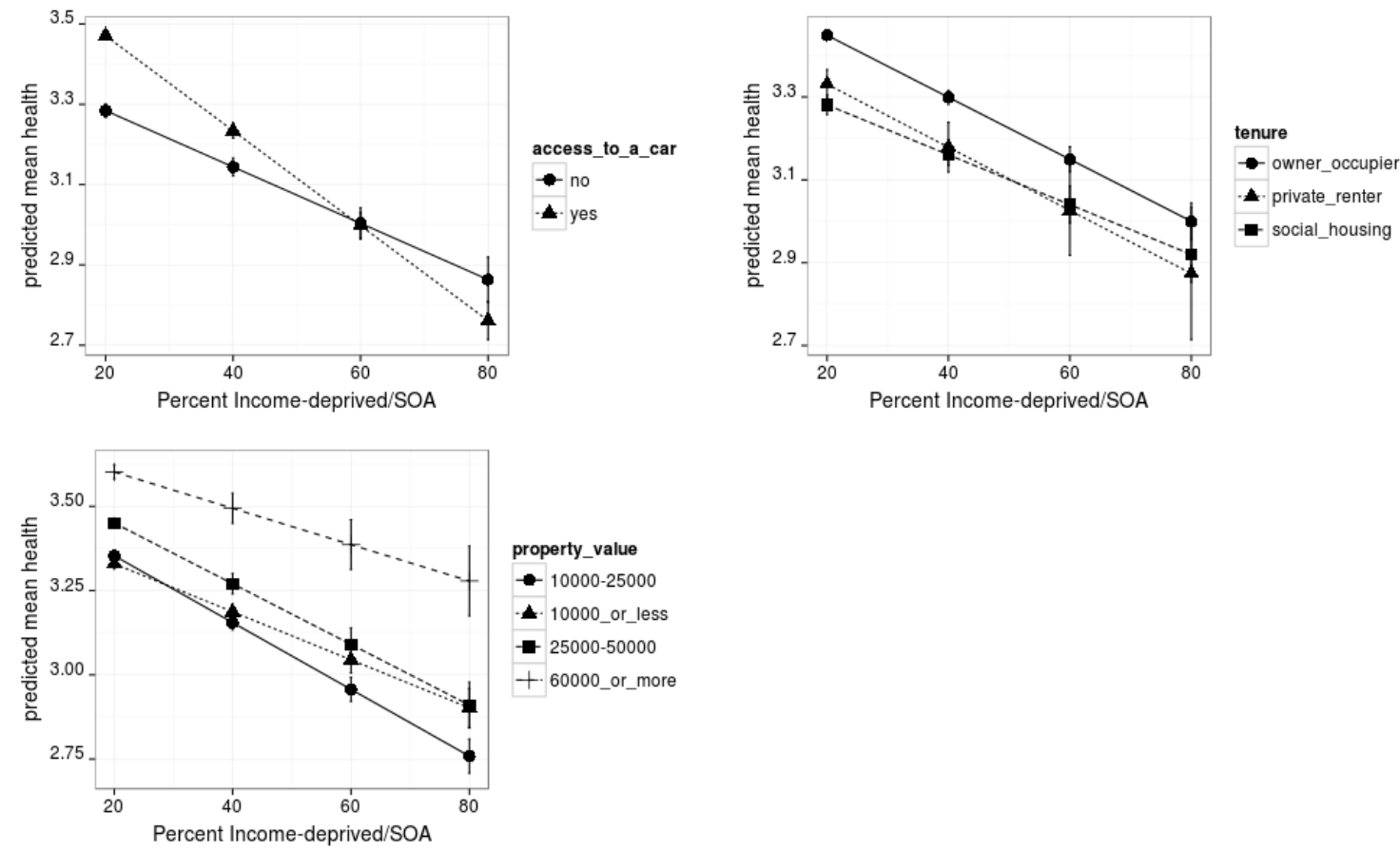